\title{
Association mapping of drought tolerance indices in wheat: QTL-rich regions on
}

\section{chromosome 4A}

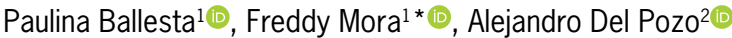

'Universidad de Talca/Instituto de Ciencias Biológicas, 2 Norte 685 - 3460000 - Talca - Chile. 2Universidad de Talca/Facultad de Ciencias Agrarias/Centro de Mejoramiento Genético y Fenómica Vegetal.

*Corresponding author <morapoblete@gmail.com>

Edited by: Leonardo Oliveira Medici

Received May 09, 2018

Accepted September 24, 2018

\begin{abstract}
Drought is likely the main abiotic stress that affects wheat yield. The identification of drought-tolerant genotypes represents an effective way of dealing with the continuous decrease in water resources as well as the increase in world population. The aim of this study was to identify single nucleotide polymorphisms (SNP) associated with drought tolerance indices in wheat by using a genome-wide association study (GWAS) under fully irrigated and rain-fed conditions. The drought tolerance indices (i.e., Stress Susceptibility Index, Stress Tolerance Index, Tolerance Index and Yield Stability Index) were calculated based on grain yield, 1,000-kernel weight and kernels per spike. The association panel was genotyped using genotyping-bysequencing (GBS). A total of 175 SNPs exhibited statistical evidence of association with at least one drought tolerance index, explaining up to $6 \%$ of the phenotypic variation. Forty-five SNPs were associated with more than one tolerance index (up to 4 agronomic traits). Most associations were located on chromosome 4A, supporting the hypothesis that this chromosome has a key role in drought tolerance which should be exploited for wheat improvement. In addition, statistical analysis detected SNPs associated with tolerance indices in both growing seasons, providing information about genetic regions with stable effects under different environmental conditions. This GWAS experiment serves as one of the few studies on association mapping for drought tolerance indices in wheat, which could increase the efficiency of rain-fed and irrigated crop production.
\end{abstract}

Keywords: SNP markers drought, genome-wide association study, rain-fed conditions

\section{Introduction}

Wheat (Triticum aestivum) is one of the most important crops in the maintaining of the security of the food supply and is the second most consumed cereal worldwide (Galetto et al., 2017; Franco et al., 2018; Oliveira and Pinto-Maglio, 2017). Drought is one of the main constraints affecting wheat production, and is found in virtually all climatic regions, providing a huge challenge to local farming in many countries worldwide (Lobell et al., 2011). However, the challenge posed by water deficit is not unbeatable. In fact, the negative effects of drought could be overcome by the identification and use of drought-tolerant varieties (Van Oosten et al., 2016). Given this solution, the dissection of molecular mechanisms that underlie adaptive traits represents one approach to understanding stress tolerance in plants (Budak et al., 2015; Liu et al., 2017; Arriagada et al., 2017). For example, Merchuk-Ovnat et al. (2016) showed that the introgression of QTLs on chromosomes $1 \mathrm{~B}$ and $2 \mathrm{~B}$ of $T$. turgidum into $T$. aestivum can enhance drought tolerance in domesticated wheat. On the other hand, a number of studies have proposed that chromosome 4A has an important role to play in drought tolerance (Alexander et al., 2012; Edae et al., 2014; Kumar et al., 2012; Nezhad et al., 2012). For instance, Edae et al. (2014) found chromosome regions (on 4A) that were associated with drought tolerance related traits such as the drought susceptibility index, leaf senescence, green leaf area and flag leaf traits. Among QTLs detected for drought susceptibility index, one QTL was found in the same region (on chromosome 4A) for yield-related traits. Kumar et al. (2012) detected a QTL (QGyp.ksu-4A, in spring wheat) for grain yield under drought stress on chromosome $4 \mathrm{~A}$, which explained $16 \%$ of the phenotypic variation. Moreover, Edae et al. (2014) found that the chromosomes of spring wheat showed substantial differences in the proportion of marker pairs in significant linkage disequilibrium (LD) from the maximum $62 \%$ for chromosome $4 \mathrm{~A}$ to the minimum $20 \%$ for chromosome $5 \mathrm{~A}$; an important aspect of association studies. Despite the extreme complexity of the wheat genome, the development of molecular marker technology has enabled the discovery of SNP markers, which have increased the chances of identifying genomic regions and explain a quantitative trait on complex genomes (Poland et al., 2012; Sabiel et al., 2017). Additionally, high-density SNP arrays have been developed for economically important crops (Sim et al., 2012; Ps et al., 2017; Contreras-Soto et al., 2017a). Thus, the aim of this study was to identify SNP associated with drought tolerance as measured by different stress tolerance indices of key agronomic traits in wheat.

\section{Materials and Methods}

\section{Plant material and field conditions}

Cultivars and advanced lines ( $\mathrm{N}=382)$ obtained from breeding programs of the Agriculture Research Institute of Chile and Uruguay and the International 
Wheat and Maize Improvement Centre (CIMMYT) were evaluated over two growing seasons (2011 and 2012) and tested in a Mediterranean and a humid environment in Chile: Cauquenes $\left(35^{\circ} 58^{\prime} \mathrm{S}, 72^{\circ} 17^{\prime} \mathrm{W}\right.$; altitude: $518 \mathrm{~m}$ above sea level) and Santa Rosa $\left(36^{\circ} 32^{\prime} \mathrm{S}, 71^{\circ} 55^{\prime} \mathrm{W}\right.$; altitude: $508 \mathrm{~m}$ above sea level). Cauquenes is a droughtprone area (rainfed conditions) with annual precipitation varying from $580 \mathrm{~mm} \mathrm{(2011)} \mathrm{to} 600 \mathrm{~mm}$ (2012), corresponding to the Mediterranean climate type (De Martonne index $20 \leq$ IDM < 24) (Baltas, 2007; Croitoru et al., 2013). Santa Rosa exhibits a full irrigation condition with annual precipitation ranging from $736 \mathrm{~mm}$ (2011) to $806 \mathrm{~mm} \mathrm{(2012),} \mathrm{corresponding} \mathrm{to} \mathrm{the} \mathrm{humid}$ climate type (De Martonne index $28 \leq$ IDM < 35). The trials were arranged using an alpha-lattice experimental design with 20 incomplete blocks, each containing 20 genotypes. Santa Rosa was fully irrigated at the end of tillering (Zadoks stage 21, Zadoks et al., 1974), flag leaf (Z37), heading (Z50) and middle grain filling (Z70). Approximately 936 and 1,006 mm of water (total water supply) were applied in Santa Rosa in 2011 and 2012, respectively.

\section{SNP genotyping and Linkage disequilibrium (LD)}

The Genotyping by Sequencing (GBS) technique was employed to construct a library and SNP calling between samples as described by Poland et al. (2012). Genomic DNA was extracted using the DNeasy Plant Maxi Kit (Qiagen). The first step in constructing the library construction required the use of the PstI-MspI GBS protocol for wheat and barley genomes as described by Poland et al. (2012). Sequencing was carried out on an Illumina HiSeq 2000. The sequences were processed in Galaxy (http://galaxy.psu.edu/) to evaluate their quality and distribution in different samples. The Tassel Pipeline (http://maizegenetics.net) was used for SNP calling with modifications for non-reference SNP calling described by Poland et al. (2012). More details about this step are provided in Lado et al. (2013). Heterozygote data were eliminated from the SNP matrix using the inbreeding coefficient in the TASSEL software package (Lado et al., 2013; Song et al., 2015). In addition, alleles with a minor frequency of 0.01 were eliminated (minor allele frequency filter), yielding a total of 2,214 SNP markers.

Genome-wide LD was estimated by calculating $r^{2}$ values between all SNP pairs localized on the same chromosome (and genome) using the R package's LDheatmap (Shin et al., 2006), and plotted by the R package's corrplot (Wei et al., 2017). The Bonferroni correction test was performed to correct for multiple testing.

\section{Phenotypic data analysis}

Four drought stress indices of three agronomic traits, including grain yield (GY), 1,000-kernel weight (TKW) and kernels per spike (KS), were calculated to perform genome-wide association mapping. GY was determined by harvesting the entire plot, and TKW and $\mathrm{KS}$ in 25 spikes were obtained at random. The indices calculated for each trait were as follows: Stress Susceptibility Index (SSI), Stress Tolerance Index (STI), Tolerance Index (TOL) and Yield Stability Index (YSI). The indices were computed according to the following equations:

$$
\begin{aligned}
& S S I=\left[1-\left(Y_{s i} / Y_{p i}\right)\right] / S I \\
& T O L=Y_{p i}-Y_{s i} \\
& Y S I=Y_{s i} / Y_{p i} \\
& S T I=\left[Y_{s i} * Y_{p i}\right] / Y_{p}^{2}
\end{aligned}
$$

where $Y_{s i}$ is the yield (trait) for each cultivar in stress condition; $Y_{p i}$ the yield (trait) for each cultivar in normal or productive condition; $S I$ the stress intensity: $S I=1$ $\left(Y_{s} / Y_{p}\right)$, where $Y_{s}$ is the total yield (trait) mean in stress condition and $Y_{p}$ the total yield mean in normal condition. A general linear model was used to evaluate the effect of variety on the indices calculated. The statistical model is described as follows:

$y_{i j k}=\mu+G_{i}+S_{j}+(G S)_{i j}+e_{i j k}$

where $y_{i j k}$ is the index value (SSI, STI, YSI and TOL) of the $i$ th genotype in the $j$ th season (2011 or 2012), $\mu$ an intercept term, $G_{i}$ the fixed effect of the $i$ th genotype, $S_{j}$ a fixed effect of the $j$ th season, (GS) the effect of genotype $\times$ site interaction, and $e_{i j k}$ the residual effect. Data were analyzed using PROC GLM in SAS (Statistical Analysis System, v. 9.2). The abbreviations of each index calculated from agronomic variables are presented in Table 1. In addition, an analysis of stable carbon isotope discrimination $\left(\Delta^{13} C\right)$ was carried out to supply evidence of the physiological state of cultivars under full irrigation and rainfed conditions. Mature kernels were analyzed in an elemental analyzer coupled with an isotope ratio mass spectrometer.

\section{Association mapping}

Genome-wide association mapping was constructed assuming a structured model. Genetic structure anal-

Table 1 - Summary of abbreviations for each studied trait.

\begin{tabular}{lcc}
\hline Index & Agronomic variable & Abbreviation \\
\hline \multirow{2}{*}{ Stress susceptibility index } & Grain yield & GY-SSI \\
& Kernels per spike & KS-SSI \\
& 1000-kernel weight & TKW-SSI \\
\hline Stress Tolerance Index & Grain yield & GY-STI \\
& Kernels per spike & KS-STI \\
\hline \multirow{3}{*}{ Tolerance Index } & 1000-kernel weight & TKW-STI \\
\hline & Grain yield & GY-TOL \\
Yield Stability Index & Kernels per spike & KS-TOL \\
& 1000-kernel weight & TKW-TOL \\
\hline
\end{tabular}


ysis was carried out using the STRUCTURE software program (Pritchard et al., 2000) following Mora et al. (2015). Evanno's method was implemented to define the number of clusters (Evanno et al., 2005). A mixed linear model (MLM) was used to detect associations between SNP markers and stress indices. The assessment was carried out using the TASSEL software package (Bradbury et al., 2007) and the following equation:

$y=X \beta+Q v+Z \mu+\varepsilon$

where $y$ is the vector of phenotypic observations (drought stress indices); $\beta$ a vector of SNP marker effects; $v$ a vector of population effects; $\mu$ a vector of random polygene background effects; and $\varepsilon$ a vector of residual effects. $X$, $Q$ and $Z$ are incidence matrices relating y to $\beta, \nu$ and $\mu$, respectively. The variation of the $\mu$ vector was modeled as $\operatorname{Var}(\mu)=2 K \sigma_{g}^{2}$, where $K$ is the matrix of pairwise kinship coefficients and $\sigma_{g}^{2}$ the genetic variance (Yu et al., 2006). Correction for multiple comparisons was made using False Discovery Rate (FDR) analysis in SAS software.

\section{Results and Discussion}

According to statistical analyses of fixed effects, the genotype effect gave proof of statistical differences for all tolerance indices $(p<0.01)$, which means that there is an important genetic background which explains the phenotypic variation (in terms of drought tolerance indices). On the other hand, the environment effect (growing seasons 2011 and 2012) showed statistical differences $(p<0.01)$ for the majority of traits, except for all SSI indices and GY-TOL, and the $\mathrm{G} \times \mathrm{S}$ effect gave proof of statistical differences for all indices studied $(p$ $<0.01$ ). In accordance with these results, Farshadfar et al. (2012) gave proof that the environment and $\mathrm{G} \times \mathrm{S}$ interaction effects explained an important part of the total variation in tolerance indices (TOL, YSI, SSI and STI) in 16 genotypes of wheat evaluated under both rainfed and irrigated conditions for three years. On the other hand, an analysis of variance revealed that $\Delta^{13} \mathrm{C}$ showed statistical differences between full irrigation (Santa Rosa) and rainfed (Cauquenes) conditions $(p<0.01)$. Under rainfed conditions, the cultivars had lower $\Delta^{13} \mathrm{C}$ values, which is an indicator of better water-use efficiency (Barbou et al., 2010; Brienen et al., 2011). These results are consistent with the De Martonne Index.

Table 2 and Figure 1A and B show the SNP pairs in linkage disequilibrium (LD) per chromosome and genome, respectively. The majority of the SNPs were located on chromosomes of B genome $(52 \%)$, followed by the chromosomes of A genome (39\%). At the chromosome level, $7 \%$ of total SNPs were located on chromosome 7B. Only one SNP was found on chromosome 4D. The LD analysis revealed that 29,27 and $33 \%$ of the SNP pairs on A, B and D genome, respectively, were in LD $\left(r^{2}\right.$ $>0.03 ; p<0.05) . r^{2}$ values ranged from $3.8 \times 10^{-7}$ and
Table 2 - Percentage of SNP pairs in linkage disequilibrium (LD) per chromosome.

\begin{tabular}{|c|c|c|c|}
\hline Chromosome & $\begin{array}{l}\text { Number of total } \\
\text { SNP }\end{array}$ & $\begin{array}{l}\text { Number of total } \\
\text { SNP pairs }\end{array}$ & $\begin{array}{l}\text { SNP pairs } \\
\text { in } L D^{*}\end{array}$ \\
\hline & & & $\%$ \\
\hline $1 \mathrm{~A}$ & 103 & 5253 & 33 \\
\hline $2 \mathrm{~A}$ & 106 & 5565 & 29 \\
\hline $3 A$ & 152 & 11476 & 22 \\
\hline $4 \mathrm{~A}$ & 126 & 7875 & 36 \\
\hline $5 \mathrm{~A}$ & 92 & 4186 & 27 \\
\hline $6 \mathrm{~A}$ & 106 & 5565 & 24 \\
\hline $7 \mathrm{~A}$ & 188 & 17578 & 32 \\
\hline $1 B$ & 126 & 7875 & 27 \\
\hline $2 B$ & 202 & 20301 & 36 \\
\hline $3 B$ & 206 & 211115 & 2 \\
\hline $4 \mathrm{~B}$ & 86 & 3655 & 35 \\
\hline $5 B$ & 169 & 14196 & 25 \\
\hline $6 B$ & 138 & 9453 & 36 \\
\hline $7 \mathrm{~B}$ & 214 & 22791 & 30 \\
\hline $1 D$ & 17 & 136 & 29 \\
\hline $2 \mathrm{D}$ & 26 & 325 & 34 \\
\hline $3 D$ & 40 & 780 & 46 \\
\hline $4 \mathrm{D}$ & 1 & - & 0 \\
\hline $5 \mathrm{D}$ & 28 & 378 & 27 \\
\hline $6 \mathrm{D}$ & 63 & 1953 & 69 \\
\hline 7D & 25 & 300 & 25 \\
\hline
\end{tabular}

1 for all chromosomes. The most linked SNP pairs were located on chromosome 6D, and the most SNPs in high LD $\left(r^{2}>0.7\right)$ on D genome. Consistent with our results, Mora et al. (2015) and Edae et al. (2014) also reported that LD extended over a longer genetic distance for the $\mathrm{D}$ genome than for the $\mathrm{A}$ and $\mathrm{B}$ genomes.

Genetic population structure analysis identified the presence of two genetically distinct subgroups (Figure 2). Cluster 1 contained 204 genotypes, while Cluster 2 included 178 genotypes. Associations were not detected after correcting for multiple comparisons (false discovery rate - FDR). However, a total of 219 associations were detected at $p<0.005$, of which 175 SNPs (approximately $8 \%$ ) were associated with at least one trait, explaining between $2 \%$ and $6 \%$ of the total phenotypic variation (Table 3). Ninety-nine and 120 associations were detected in the growing seasons of 2011 and 2012, respectively. The difference in number of SNP associations detected between both growing seasons is in accordance with the $\mathrm{G} \times \mathrm{S}$ interaction found in this study (Heidari et al., 2011). However, nine SNPs (located on chromosomes 6D, 3B, 2B, 7D, 6B and 3D) associated with TKW-STI were detected in both growing seasons. Consistently, Mora et al. (2015) reported eight SNPs over the growing seasons associated with TKW in a non-stress site (irrigated site). Interestingly, Saeed et al. (2017) also detected SNPs associated with TKW-STI and GY-STI in more than one growing season in wheat. The early detection of QTL and evaluation of their stability 

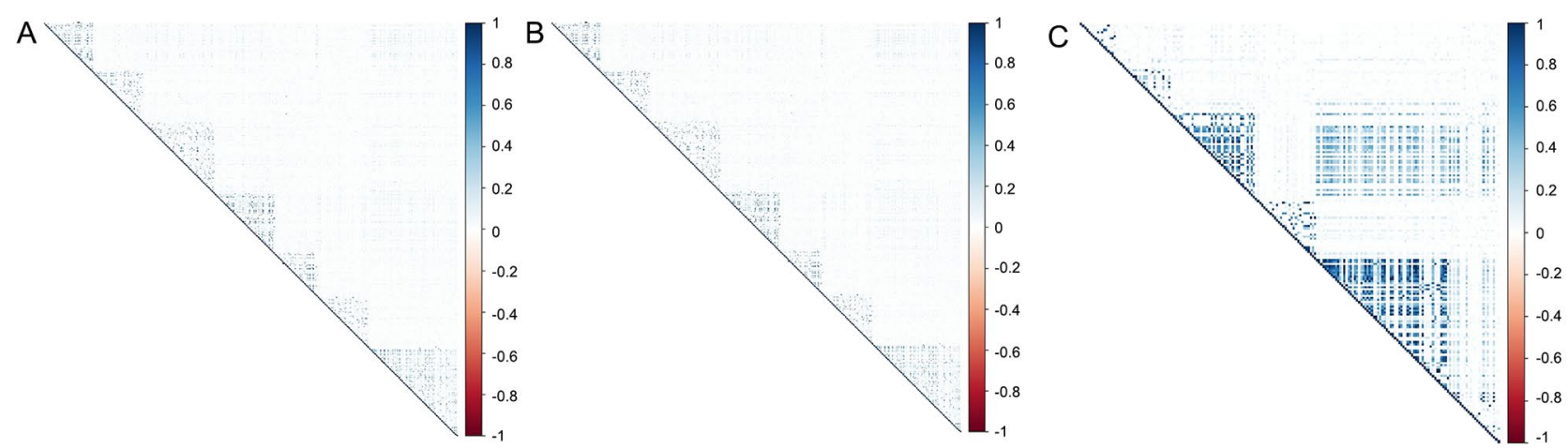

Figure 1 - Linkage disequilibrium (LD) among all SNP pairs calculated for each genome. $A, B$ and $C$ are $L D$ plots for $A, B$ and $D$ genome of wheat, respectively.
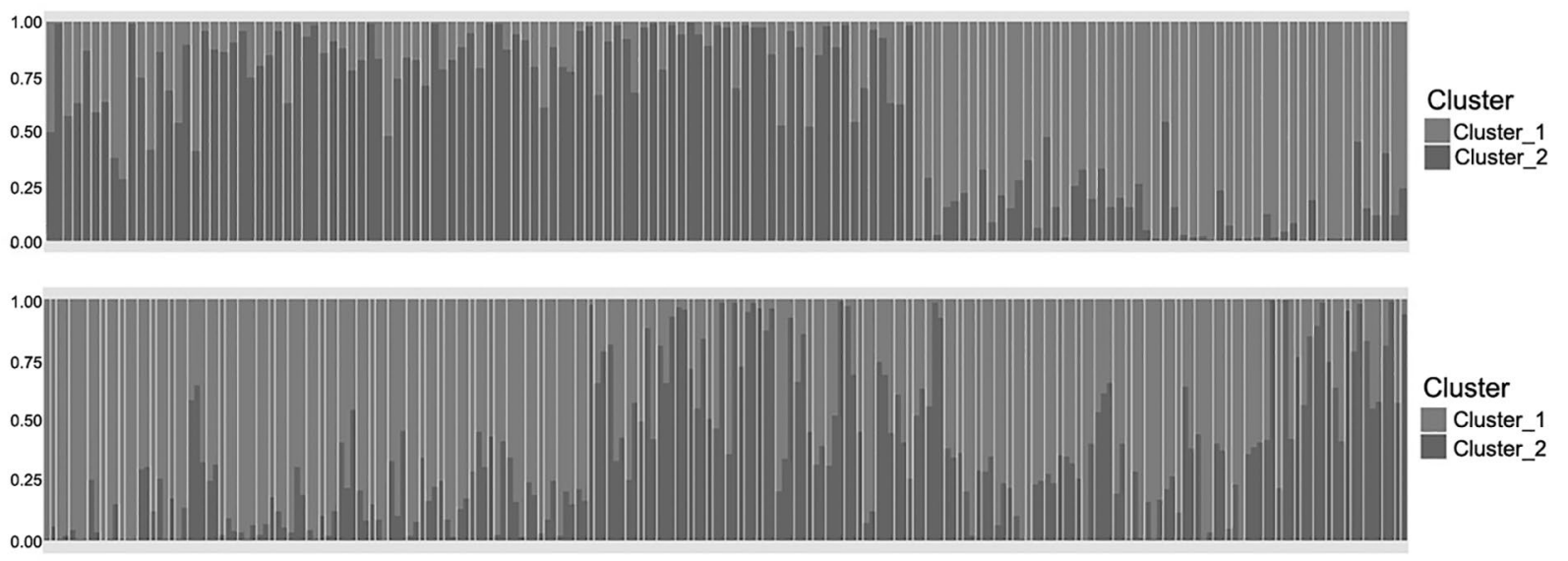

Figure 2 - Population structure of 382 wheat cultivars inferred using the model-based Bayesian algorithm implemented in STRUCTURE. The 382 genotypes are represented in $\mathrm{x}$-axis and the cluster assignment for each cultivar in $\mathrm{y}$-axis $(K=2)$.

across multiple environmental conditions would allow for the identification of candidate QTL for MAS (Sun et al., 2012). Multiple evaluations may minimize the risk of selecting genotypes that exhibit good performance in particular environments but not under several conditions (El-Soda et al., 2014).

The highest number of trait associations was established with SNP markers located on B genome $143 \%$ of total associations). However, at the chromosome level, chromosome $4 \mathrm{~A}$ was identified as the most repeated region for SNP-trait associations (26 associations). TKWSTI (evaluated in 2011) was the index with the highest number of associations (31 associations), whereas the fewest number of associations were detected for KSSSI (one association) and KS-YSI (one association) in the same growing season.

Thirty-two marker-trait associations were detected for GY-SSI, TKW-SSI and KS-SSI and were located mainly on chromosomes $4 \mathrm{~A}, 4 \mathrm{~B}$ and $6 \mathrm{~B}$. In particular, 11 associations were detected for TKW-SSI (located mostly on chromosomes 4B, 7B and 6A), and 14 associations were detected for KS-SSI. These associations were predominantly located on chromosomes $4 \mathrm{~A}$ and
6B. No SNPs located on genome D were associated with TKW-SSI and KS-SSI indices in both growing seasons. GY-SSI indices (2011 and 2012) were associated with SNPs located on the three genomes and involved seven chromosomes (1A, 2A, 5A, 6A, 2B, 5D and 6B), with one association for each chromosome. One hundred associations were detected for the STI indices, which were recurrent on chromosomes 6D, 4A and 6A. Fiftysix associations were identified for TKW-STI and were located preferentially on chromosomes 6D, 3B and 6A. Thirty-one associations were identified for KS-STI and were mainly located on chromosomes $4 \mathrm{~A}, 6 \mathrm{~B}$ and $6 \mathrm{~A}$. Thirteen associations were detected for GY-STI with SNPs frequently located on chromosome 2D. Forty-six associations were detected for TOL indices, and these associations were frequently noted on chromosomes $2 \mathrm{~B}$ and 4A. In summary, nine associations were identified for TKW-TOL with SNPs preferentially located on chromosome 6A. Twenty-five associations were detected for KS-TOL and were mainly located on chromosomes 4A and 7A. Twelve associations were detected for GY-TOL with SNPs commonly located on chromosomes $3 \mathrm{~A}$ and 2B. Finally, 41 associations were detected for the YSI 
Table 3 - Chromosome location and number of associations $(p<0.005)$ for tolerance indices: SSI (Stress susceptibility index), STI (Stress Tolerance Index), TOL (Tolerance Index) and YSI (Yield Stability Index) evaluated in the growing seasons of 2011 and 2012.

\begin{tabular}{|c|c|c|}
\hline Index/year & Chromosome (number of associations) & $\mathrm{PV} \%$ \\
\hline \multicolumn{3}{|l|}{2011} \\
\hline TKW-SSI & $2 \mathrm{~A}(1), 4 \mathrm{~B}(3), 6 \mathrm{~B}(1), 7 \mathrm{~B}(1)$ & $3-4$ \\
\hline TKW-STI & $1 \mathrm{~A}(1), 1 \mathrm{~B}(1), 2 \mathrm{~A}(1), 2 \mathrm{~B}(2), 3 \mathrm{~B}(4), 3 \mathrm{D}(1), 4 \mathrm{~A}(1), 5 \mathrm{~A}(3), 6 \mathrm{~A}(4), 6 \mathrm{~B}(2), 6 \mathrm{D}(9), 7 \mathrm{~B}(1), 7 \mathrm{D}(1)$ & $2-4$ \\
\hline TKW-TOL & $1 A(1), 1 D(1), 2 B(1), 5 A(1), 6 A(1), 6 B(1)$ & $3-5$ \\
\hline TKW-YSI & $2 \mathrm{~A}(1), 4 \mathrm{~B}(3), 6 \mathrm{~B}(1), 7 \mathrm{~B}(1)$ & 3-4 \\
\hline KS-SSI & $4 A(1)$ & 3 \\
\hline KS-STI & $2 \mathrm{~B}(2), 2 \mathrm{D}(2), 4 \mathrm{~A}(5), 5 \mathrm{~B}(1), 6 \mathrm{~A}(2), 6 \mathrm{~B}(6), 7 \mathrm{~A}(3), 7 \mathrm{~B}(1)$ & $3-6$ \\
\hline KS-TOL & $3 B(2), 4 A(1), 6 A(1), 7 A(4)$ & 3-4 \\
\hline KS-YSI & $4 A(1)$ & 3 \\
\hline GY-SSI & $2 A(1), 5 A(1), 6 D(1)$ & $3-5$ \\
\hline GY-STI & $2 \mathrm{~B}(1), 2 \mathrm{D}(4), 5 \mathrm{~B}(2)$ & $3-4$ \\
\hline GY-TOL & $4 A(1), 6 \mathrm{D}(2), 7 \mathrm{~B}(2)$ & $4-5$ \\
\hline GY-YSI & $2 A(1), 5 A(1), 6 D(1)$ & $3-5$ \\
\hline \multicolumn{3}{|l|}{2012} \\
\hline TKW-SSI & $3 \mathrm{~A}(1), 3 \mathrm{~B}(1), 6 \mathrm{~A}(2), 7 \mathrm{~B}(1)$ & $3-4$ \\
\hline TKW-STI & $1 \mathrm{~B}(1), 2 \mathrm{~B}(2), 3 \mathrm{~A}(1), 3 \mathrm{~B}(3), 3 \mathrm{D}(1), 4 \mathrm{~A}(3), 5 \mathrm{~B}(1), 6 \mathrm{~A}(3), 6 \mathrm{~B}(2), 6 \mathrm{D}(4), 7 \mathrm{~B}(3), 7 \mathrm{D}(1)$ & $3-4$ \\
\hline TKW-TOL & $2 \mathrm{~B}(1), 6 \mathrm{~A}(2)$ & 3-4 \\
\hline TKW-YSI & $2 A(1), 2 B(1), 3 A(2), 3 B(1), 6 D(2), 7 B(1)$ & $3-5$ \\
\hline KS-SSI & $3 B(1), 4 A(3), 5 A(2), 6 B(4), 7 A(1), 7 B(2)$ & $3-5$ \\
\hline KS-STI & $2 A(2), 4 A(1), 5 B(1), 6 A(3), 7 B(2)$ & 3-4 \\
\hline KS-TOL & $3 B(1), 4 A(5), 5 A(2), 6 B(4), 6 D(2), 7 A(1), 7 B(2)$ & $3-5$ \\
\hline KS-YSI & $2 A(1), 2 B(1), 4 A(2), 5 A(3), 6 B(4), 7 A(2), 7 B(2)$ & $3-5$ \\
\hline GY-SSI & $1 \mathrm{~A}(1), 2 \mathrm{~B}(1), 5 \mathrm{D}(1), 6 \mathrm{~A}(1)$ & 3-4 \\
\hline GY-STI & $3 \mathrm{~A}(1), 3 \mathrm{~B}(1), 4 \mathrm{~A}(2), 7 \mathrm{~B}(2)$ & $3-5$ \\
\hline GY-TOL & $2 \mathrm{~B}(3), 3 \mathrm{~A}(3), 3 \mathrm{~B}(1)$ & 3-4 \\
\hline GY-YSI & $1 \mathrm{~B}(1), 2 \mathrm{~B}(3), 3 \mathrm{~A}(1), 3 \mathrm{~B}(1), 5 \mathrm{D}(1), 6 \mathrm{~A}(1)$ & $3-5$ \\
\hline
\end{tabular}

$\overline{\mathrm{GY}}=$ grain yield; $\mathrm{KS}=$ kernels per spike; TKW $=1,000$-kernel weight; $\mathrm{PV} \%$ = the proportion of phenotypic variation explained by SNP markers (in \%).

indices, which were recurrent on chromosomes $2 \mathrm{~B}$ and 6B. Fourteen associations were identified for TKW-YSI with SNPs preferentially located on chromosomes 4B, $3 \mathrm{~A}$ and 6D. Sixteen associations were detected for KSYSI and were located mainly on chromosomes $5 \mathrm{~A}$ and 6B. Eleven associations mainly located on chromosome 2B were identified for GY-YSI.

Few studies of association analyses using stress indices have been conducted on wheat. In fact, the studies available have been conducted using molecular markers, such as SSR (simple sequence repeat), DArT (Diversity Arrays Technology), AFLP (amplified fragment length polymorphism) and RFLP (restriction fragment length polymorphism). Dashti et al. (2007) detected AFLP, RFLP and SSR markers associated with the SSI, STI and TOL indices calculated from GY, explaining $21 \%, 15 \%$ and $36 \%$ of the phenotypic variation, respectively. SNP markers associated with GY-SSI were located on chromosomes 7A, 4B and 5B. Associations for GY-STI and GY-TOL were located on chromosomes $1 \mathrm{~B}$ and $5 \mathrm{~B}$, respectively. In addition, Dodig et al. (2012) reported SSR markers associated with GY-SSI and GY-TOL explaining between $15 \%$ and $25 \%$ of phenotypic variation. One SSR located on chromosome 2D was associated with GY-SSI and GY-TOL, and an exclusive SNP for GY-TOL was located on chromosome 2B. Saeed et al. (2017) dis- covered SSR markers explaining between $7 \%$ and $17 \%$ of phenotypic variation for TKW-STI, TKW-SSI, GY-STI and GY-SSI (GY expressed as GY per plant). SSRs associated with TKW-STI were located on chromosomes 7D and 5D (two QTL detected in two growing seasons), and trait associations for TKW-SSI were detected on chromosomes 7D (one QTL detected in two growing seasons) and $3 \mathrm{~A}$. In addition, SSR markers associated with GYSTI were located on chromosome 7D lone QTL detected in two growing seasons), and GY-SSI associations were identified using SSRs located on chromosomes 6D and 7D (one QTL detected in two growing seasons). Kirigwi et al. (2007) reported SSRs associated with GY-SSI (in several growing seasons), which were located on chromosome $4 \mathrm{~A}$, explaining between 12 and $41 \%$ of the total phenotypic variation. The authors proposed that chromosome $4 \mathrm{~A}$ is a region in the wheat genome that contains markers associated with drought tolerance. Interestingly, Edae et al. (2014) reported one DArT marker on chromosome $4 \mathrm{~A}$, explaining $4 \%$ of the phenotypic variation for GY-SSI. Consistently, in the present study, most of the SNP markers involved in marker-trait associations were located on chromosome 4A (26/129 associations; approximately $12 \%$ of total associations), supporting the hypothesis that this chromosome plays a central role in the drought tolerance of wheat. On the other hand, 
other studies involving QTL analyses have emphasized the importance of genome B in certain drought-related traits. Kumar et al. (2012) for instance, identified QTLs located on chromosomes $2 \mathrm{~B}$ and $3 \mathrm{~B}$ explaining up to $56 \%$ and $60 \%$ of the phenotypic variation of potential quantum efficiency of photosystem II $\left(\mathrm{F}_{\mathrm{v}} / \mathrm{F}_{\mathrm{m}}\right)$ and chlorophyll content (Chl), respectively, which were positively correlated with GY-STI ( $\mathrm{r}>0.95)$. In the present study, 17 and 16 associations were located on chromosome 2B and $3 \mathrm{~B}$ respectively. Particularly, two SNPs of these chromosomes were associated with GY-STI, obtaining the highest explained phenotypic variation for GY-STI. The $\mathrm{B}$ genome has been recognized by carrying loci controlling water-use efficiency and related traits, and grain yield under water stress conditions (Mohammady et al., 2012; Poersch-Bortolon et al., 2016), which could explain why $43 \%$ of the total associations in the present study were located on the $\mathrm{B}$ genome.

There have been conflicting reports on the phenotypic variation explained by the markers (e.g., SSR, RFLP, AFLP and our results with SNP markers) for traits involved in drought stress indices. The findings reported by Saeed et al. (2017) and Edae et al. (2014) are consistent with the present study. On the other hand, Jaganathan et al. (2015) detected one SNP associated with GY-SSI and three associated with GY-STI using GBS technology, explaining between $10 \%$ and $13 \%$, respectively, of the phenotypic variation in chickpea. PS et al. (2017) reported SNPs associated with SSI and STI (calculated from the $\%$ spikelet sterility and yield per plant) in rice, explaining between $6 \%$ and $21 \%$, respectively, of the phenotypic variation. Curiously, some SNPs are associated with traits related to crop productivity and wateruse efficiency, explaining a similar range in phenotypic variation. For instance, we detected one association between the SNP iniaGBS11860 and KS-YSI (2012), which was previously associated with the photosynthetic carbon isotope discrimination in wheat (Mora et al., 2015).

Forty-five SNP markers were associated with more than one stress index. For example, one SNP located on chromosome 3A (i.e., iniaGBS21464) was associated with four indices in 2012: TKW-SSI, TKW-YSI, GY-STI and GY-YSI. Three SNPs located on chromosome 4A (iniaGBS22028, iniaGBS558 and iniaGBS2019) and four SNPs located on chromosome 6B (iniaGBS41345, iniaGBS22659, iniaGBS1579 and iniaGBS22660) were associated with TKW-SSI and TKW-YSI in 2012. Additionally, the SNP iniaGBS44415 was associated with TKW-SSI, TKW-YSI, GY-STI and GY-YSI in 2011. In general, markers are frequently associated with more than one trait (e.g., Contreras-Soto et al., 2017b; Liu et al., 2011; Mora et al., 2015), which could be explained by the linkage between markers or possible pleiotropic effects (Zhu et al., 2014). In the context of genetic improvement, the pleiotropic effects of molecular markers could be used to take advantage of more than one trait of interest. For instance, Ookawa et al. (2010) reported a gene associated with high grain yield and enhanced lodging resistance, which was suggested as an important pleiotropic gene for the improvement of rice varieties. On the other hand, pleiotropic effects could be harmful for one trait and beneficial for another. QTLs associated with herbicide resistance have exhibited harmful pleiotropic effects on yield in a number of crops (Darmency, 2013).

\section{Conclusions}

Wheat culture is strongly affected by drought; therefore, the generation of drought tolerant cultivars is one of the main challenges to genetics and breeders. SNP markers linked to the QTL of drought tolerance indices were identified in a diverse genotype collection, and the phenotypic variation explained by SNP markers (up to $6 \%$ ) was within an expected range according to other studies. QTL-rich regions on chromosome 4A were detected, supporting the hypothesis that this chromosome has a key role to play in drought tolerance and should be exploited for wheat improvement. In addition, at the genome level, a high number of SNP-associations were located on the B genome, which have been linked with drought tolerance.

The association analysis found a number of SNP markers associated with drought tolerance indices in both growing seasons, revealing genetic regions with stable effects under different environmental conditions. The use of drought tolerance indices in GWAS provides valuable information for marker-assisted selection in wheat.

\section{Acknowledgments}

This study was supported by the projects FONDECYT No. 1150353 and 1180252. We thank Mr. Alejandro Castro for technical assistance in field experiments. Paulina Ballesta thanks CONICYT-PCHA 2016-folio 21160624 .

\section{Authors' Contributions}

Conceptualization: Mora, F.; Ballesta, P.; Del Pozo, A. Data acquisition: Del Pozo, A. Data Analysis: Ballesta, P.; Mora, F. Design Methodology: Mora, F.; Ballesta, P.; Del Pozo, A. Writing and Editing: Ballesta, P.; Mora, F.; Del Pozo, A.

\section{References}

Alexander, L.M.; Kirigwi, F.M.; Fritz, A.K.; Fellers, J.P. 2012. Mapping and quantitative trait loci analysis of drought tolerance in a spring wheat population using amplified fragment length polymorphism and diversity array technology markers. Crop Science 52: 253-261.

Arriagada, O.; Mora, F.; Quitral, Y.; Del Pozo, A. 2017. Identification of QTL underlying agronomic, morphological and physiological traits in barley under rainfed conditions using SNP markers. Acta Scientiarum Agronomy 39: 321-329. 
Baltas, E. 2007. Spatial distribution of climatic indices in northern Greece. Meteorology Applications 14: 69-78.

Barbour, M.M.; Warren, C.R.; Farquhar, G.D.; Forrester, G.U.Y.; Brown, H. 2010. Variability in mesophyll conductance between barley genotypes, and effects on transpiration efficiency and carbon isotope discrimination. Plant, Cell \& Environment 33: 1176-1185.

Bradbury, P.J.; Zhang, Z.; Kroon, D.E.; Casstevens, T.M.; Ramdoss, Y.; Buckler, E.S. 2007. TASSEL: software for association mapping of complex traits in diverse samples. Bioinformatics 23: 2633-2635.

Brienen, R.J.; Wanek, W.; Hietz, P. 2011. Stable carbon isotopes in tree rings indicate improved water use efficiency and drought responses of a tropical dry forest tree species. Trees 25: 103113.

Budak, H.; Hussain, B.; Khan, Z.; Ozturk, N.Z.; Ullah, N. 2015. From genetics to functional genomics: improvement in drought signaling and tolerance in wheat. Frontiers in Plant Science 6: 1012.

Contreras-Soto, R.I.; Mora, F.; Lazzari, F.; Oliveira, M.A.R.; Scapim, C.A.; Schuster, I. 2017a. Genome-wide association mapping for flowering and maturity in tropical soybean: implications for breeding strategies. Breeding Science 67: 435449.

Contreras-Soto, R.I.; Mora, F.; Oliveira, M.A.R.; Higashi, W.; Scapim, C.A.; Schuster, I. 2017b. A genome-wide association study for agronomic traits in soybean using SNP markers and SNP-based haplotype analysis. Plos One 12: e0171105.

Croitoru, A.E.; Piticar, A.; Imbroane, A.M.; Burada, D.C. 2013. Spatiotemporal distribution of aridity indices based on temperature and precipitation in the extra-Carpathian regions of Romania. Theoretical Applied Climatology 112:597-607.

Darmency, H. 2013. Pleiotropic effects of herbicide-resistance genes on crop yield: a review. Pest Management Science 69: 897-904.

Dashti, H.; Yazdi-Samadi, B.; Ghannadha, M.; Naghavi, M.R.; Quarrie, S. 2007. QTL analysis for drought resistance in wheat using doubled haploid lines. International Journal of Agriculture and Biology 9: 98-102.

Dodig, D.; Zoric, M.; Kobiljski, B.; Savic, J.; Kandic, V.; Quarrie, S.; Barnes, J. 2012. Genetic and association mapping study of wheat agronomic traits under contrasting water regimes. International Journal of Molecular Sciences 13: 6167-6188.

Edae, E.A.; Byrne, P.F.; Haley, S.D.; Lopes, M.S.; Reynolds, M.P. 2014. Genome-wide association mapping of yield and yield components of spring wheat under contrasting moisture regimes. Theoretical and Applied Genetics 127: 791-807.

El-Soda, M.; Malosetti, M.; Zwaan, B.J.; Koornnef, M.; Aarts, M.G.M. 2014. Genotype $\times$ environment interaction QTL mapping in plants: lessons from Arabidopsis. Trends in Plant Science 19: 390-398.

Evanno, G.; Regnaut, S.; Goudet, J. 2005. Detecting the number of clusters of individuals using the software STRUCTURE: a simulation study. Molecular Ecology 14: 2611-2620.

Farshadfar, E.; Poursiahbidi, M.M.; Abooghadareh, A.R.P. 2012. Repeatability of drought tolerance indices in bread wheat genotypes. International Journal of Agriculture and Crop Sciences 4: 891-903.
Franco, F.A.; Marchioro, V.S.; Montecelli, T.D.N.; Schuster, I.; Polo, M.; Souza, L.V.; Lima, F.J.A.; Evangelista, A.; Santos, D.A.; Grave, E.L. 2018. CD 1303 - Short stature, high productive potential and industrial quality. Crop Breeding and Applied Biotechnology 18: 123-125.

Galetto, S.L.; Bini, A.R.; Haliski, A.; Scharr, D.A.; Borszowskei, P.R.; Caires, E.F. 2017. Nitrogen fertilization in top dressing for wheat crop in succession to soybean under a no-till system. Bragantia 76: 282-291.

Heidari, B.; Sayed-Tabatabaei, B.E.; Saeidi, G.; Kearsey, M.; Suenaga, K. 2011. Mapping QTL for grain yield, yield components, and spike features in a doubled haploid population of bread wheat. Genome 54: 517-527.

Jaganathan, D.; Thudi, M.; Kale, S.; Azam, S.; Roorkiwal, M.; Gaur, P.M.; Kavikishor, P.B.; Nguyen, H.; Sutton, T.; Varshney, R.K. 2015. Genotyping-by-sequencing based intra-specific genetic map refines a "QTL-hotspot" region for drought tolerance in chickpea. Molecular Genetics and Genomics 290: 559-571.

Kirigwi, F.M.; van Ginkel, M.; Brown-Guedira, G.; Gill, B.S.; Paulsen, G.M.; Fritz, A. K. 2007. Markers associated with a QTL for grain yield in wheat under drought. Molecular Breeding 20: 401-413.

Kumar, S.; Sehgal, S.K.; Kumar, U.; Prasad, P.V.; Joshi, A.K.; Gill, B.S. 2012. Genomic characterization of drought tolerancerelated traits in spring wheat. Euphytica 186: 265-276.

Lado, B.; Matus, I.; Rodríguez, A.; Inostroza, L.; Poland, J.; Belzille, F.; Del Pozo, A.; Quincke, M.; Castro, M.; von Zitzewitz, J. 2013. Increased genomic prediction accuracy in wheat breeding through spatial adjustment of field trial data. G3-Genes Genomes Genetics 3: 2105-2114.

Liu, H.; Able, A.J.; Able, J.A. 2017. Water-deficit stressresponsive microRNAs and their targets in four durum wheat genotypes. Functional \& Integrative Genomics 17: 237-251.

Liu, T.; Zhang, Y.; Zhang, H.; Xing, Y. 2011. Quantitative trait loci for the number of grains per panicle dependent on or independent of heading date in rice (Oryza sativa L.). Breeding Science 61: 142-150.

Lobell, D.B.; Schlenker, W.; Costa-Roberts, J. 2011. Climate trends and global crop production since 1980. Science 333: 616-20.

Merchuk-Ovnat, L.; Barak, V.; Fahima, T.; Ordon, F.; Lidzbarsky, G.A.; Krugman, T.; Saranga, Y. 2016. Ancestral QTL alleles from wild emmer wheat improve drought resistance and productivity in modern wheat cultivars. Frontiers in Plant Science 7: 452 .

Mohammady, S.; Aminian, R.; Hoshmand, S.; Khodombashi, M. 2012. Genomic analysis of carbon isotope discrimination, photosynthesis rate, stomatal conductance, and grain yield in wheat (Triticum aestivum L.) under water-stressed conditions. Crop \& Pasture Science 63: 513-519.

Mora, F.; Castillo, D.; Lado, B.; Matus, I.; Poland, J.; Belzile, F.; von Zitzewitz, J.; del Pozo, A. 2015. Genome-wide association mapping of agronomic traits and carbon isotope discrimination in a worldwide germplasm collection of spring wheat using SNP markers. Molecular Breeding 35: 69.

Nezhad, K.Z.; Weber, W.E.; Röder, M.S.; Sharma, S.; Lohwasser, U.; Meyer, R.C.; Börner, A. 2012. QTL analysis for thousandgrain weight under terminal drought stress in bread wheat (Triticumaestivum L.). Euphytica 186: 127-138. 
Oliveira, É.C.D.; Pinto-Maglio, C.A.F. 2017. Cytomolecular characterization of cultivars and landraces of wheat tolerant and sensitive to aluminum toxicity. Bragantia 76: 456-469.

Ookawa, T.; Hobo, T.; Yano, M.; Murata, K.; Ando, T.; Miura, H.; Asano, K.; Ochiai, Y.; Ikeda, M.; Nishitani, R.; Ebitani, T.; Ozaki, H.; Angeles, E.R.; Hirasawa, T.; Matsuoka, M. 2010. New approach for rice improvement using a pleiotropic QTL gene for lodging resistance and yield. Nature Communications 1: 132.

Poland, J.A.; Brown, P.J.; Sorrells, M.E.; Jannink, J.L. 2012. Development of high-density genetic maps for barley and wheat using a novel two-enzyme genotyping-by-sequencing approach. Plos One 7: e32253.

Poersch-Bortolon, L.B.; Pereira, J.F.; Nhani Junior, A.; Gonzáles, H.H.S.; Torres, G.A. M.; Consoli, L.; Arenhart, R.A.; BodaneseZanettini, M.H.; Margis-Pinheiro, M. 2016. Gene expression analysis reveals important pathways for drought response in leaves and roots of a wheat cultivar adapted to rainfed cropping in the Cerrado biome. Genetics and Molecular Biology 39: 629645.

Pritchard, J.K.; Stephens, M.; Donnelly, P. 2000. Inference of population structure using multilocus genotype data. Genetics 155: 945-959.

Ps, S.; Sv, A.M.; Prakash, C.; Ramkumar, M.K.; Tiwari, R.; Mohapatra, T.; Singh, N.K. 2017. High resolution mapping of QTLs for heat tolerance in rice using a 5K SNP array. Rice 10: 28.

Sabiel, S.A.I.; Huang, S.; Hu, X.; Ren, X.; Fu, C.; Peng, J.; Sun, D. 2017. SNP-based association analysis for seedling traits in durum wheat (Triticum turgidum L. durum (Desf.)). Breeding Science 67: 83-94.

Saeed, I.; Chen, X.; Bachir, D.G.; Chen, L.; Hu, Y.G. 2017. Association mapping for photosynthesis and yield traits under two moisture conditions and their drought indices in winter bread wheat (Triticum aestivum L.) using SSR markers. Australian Journal of Crop Science 11: 248.
Shin, J.H.; Blay, S.; McNeney, B.; Graham, J. 2006. LDheatmap: an R Function for Graphical Display of Pairwise Linkage Disequilibria Between Single Nucleotide Polymorphisms. Journal of Statistical Software 16: Code Snippet 3.

Sim, S.C.; Durstewitz, G.; Plieske, J.; Wieseke, R.; Ganal, M.W.; Deyne, A.V.; Hamilton, J.P.; Buell, C.R.; Causse, M.; Wijeratne, S.; Francis, D.M. 2012. Development of a large SNP genotyping array and generation of high-density genetic maps in tomato. Plos One 7: e40563.

Song, Q.; Jia, G.; Hyten, D.L.; Jenkins, J.; Hwang, E.Y.; Schroeder, S.G.; Osorno, J.M.; Schmutz, J.; Jackson, S.A.; McClean, P.E.; Cregan, P.B. 2015. SNP assay development for linkage map construction, anchoring whole-genome sequence, and other genetic and genomic applications in common bean. G3: Genes, Genomes, Genetics 5: 2285-2290.

Sun, F.D.; Zhang, J.H.; Wang, S.F.; Gong, W.K.; Shi, Y.Z.; Liu, A.Y.; Li, J.W.; Gong, J.W.; Shang, H.H.; Yuan, Y.L. 2012. QTL mapping for fiber quality traits across multiple generations and environments in upland cotton. Molecular Breeding 30: 569-582.

Van Oosten, M.J.; Costa, A.; Punzo, P.; Landi, S.; Ruggiero, A.; Batelli, G.; Grillo, S. 2016. Genetics of drought stress tolerance in crop plants. p. 39-70. In: Hossain, M.A.; Wani, S.H.; Bhattachajee, S.; Burritt, D.J.; Tran, L.-S.P., eds. Drought stress tolerance in plants. Springer, Cham, Switzerland.

Wei, T.; Simko, V.; Levy, M.; Xie, Y.; Jin, Y.; Zemla, J. 2017. Package 'corrplot'. Statistician 56: 316-324.

Yu, J.; Pressoir, G.; Briggs, W.H.; Vroh, B.I.; Yamasaki, M.; Doebley, J.F.; McMullen, M.D.; Gaut, B.S.; Nielsen, D.M.; Holland, J.B.; Kresovich, S.; Buckler, E.S. 2006. A unified mixed-model method for association mapping that accounts for multiple levels of relatedness. Nature Genetics 38: 203-208.

Zadoks, J.C.; Chang, T.T.; Konzak, C.F. 1974. A decimal code for the growth stages of cereals. Weed Research 14: 415-421.

Zhu, R.; Gao, Y.; Zhang, Q. 2014. Quantitative trait locus mapping of floral and related traits using an F2 population of Aquilegia. Plant Breeding 133: 153-161. 